\title{
Representações Quantitativas em Laboratórios Virtuais para o Ensino de Química
}

\section{Quantitative Representations in Virtual Laboratories for Chemistry Teaching}

\author{
Alessandro Félix Pascoina; José Wilson P. Carvalho*a \\ ${ }^{a}$ Universidade do Estado de Mato Grosso, Programa de Pós-Graduação Stricto Sensu em Ensino de Ciências e Matemática. MT, Brasil. \\ *E-mail: jwilsonc@unemat.br
}

\begin{abstract}
Resumo
Os laboratórios virtuais utilizados no ensino de Química se constituem importantes recursos didáticos para o avanço dos processos de ensino e aprendizagem, ao passo que podem contribuir para ações de mediação na construção do conhecimento. A presente pesquisa teve como objetivo analisar as representações quantitativas que estão presentes nas interfaces de laboratórios virtuais à luz da Semiótica Peirceana. É uma pesquisa qualitativa exploratória, realizada no repositório portal PhET-Interative Simulation. No percurso da pesquisa foram encontrados 51 aplicativos, desses seis exibiam características de laboratório virtual e três foram semioticamente analisados. Os resultados indicam que três laboratórios apresentam disposições parcialmente satisfatórias nas representações quantitativas que abordam. Esses podem vir a contribuir para o fortalecimento do ensino da Química, por meio de ilustrações, simulações e a participação interativa do estudante. Quanto às possibilidades, esses oferecem diferentes ambientes, formatos e modelos para o estudo desta ciência. Também foram encontradas limitações como a insuficiência de signos iconográficos de ordem quantitativa considerados indispensáveis na conjuntura conceitual de determinados tópicos da Química. As indicações desta pesquisa são para se pensar a respeito dos signos que vão representar a natureza quantitativa da Química, transformando os desafios em possibilidades para os processos de ensino e aprendizagem desta ciência.
\end{abstract}

Palavras-chave: Semiótica. Ensino de Química. Laboratórios Virtuais.

\begin{abstract}
Virtual laboratories used in chemistry teaching are important didactic resources for the advancement of teaching and learning processes, while they can contribute to mediation actions in the knowledge construction. This research aims to analyze the quantitative representations that are present in the virtual laboratories interfaces in light of Peircean semiotics. It is an exploratory qualitative research, conducted at the portal PhET - Interative Simulation. During the research, 51 applications were found, of these, 6 exhibited virtual laboratory characteristics and three were semiotically analyzed. The results indicate that three laboratories have partially satisfactory arrangements in the quantitative representations they address. They can contribute to the strengthening of chemistry teaching through illustrations, simulations and interactive student participation. As for the possibilities they offer different environments, formats and models for the study of this science. Limitations were also found as the insufficiency of quantitative iconographic signs considered indispensable in the conceptual conjuncture of certain topics of chemistry. The indications of this research are to think about the signs that will represent the Chemistry quantitative nature, turning the challenges into possibilities for the teaching and learning processes of this science.
\end{abstract}

Keywords: Semiotics. Chemistry Teaching. Virtual Labs.

\section{Introdução}

No âmbito do uso e do interesse por recursos de tecnologias digitais, especialmente em setores da sociedade, como o educacional, há muitos questionamentos no que diz respeito às contribuições que tais recursos podem oferecer. Para Kenski (2012), a revolução digital transforma o espaço educacional.

De maneira que frente a "novos recursos, outros interesses, outras relações pessoais, sociais e educacionais estão presentes em seu cotidiano" (RIBEIRO et al., 2016). Nesta perspectiva, enquanto as escolas mobilizam orientações para uso da tecnologia digital, os alunos se adiantam em procurá-la para desempenhar inúmeras atividades sociais e de entretenimento. Segundo Leite (2015), tem sido recorrente a inserção de recursos de tecnologias digitais no contexto educacional, entretanto, esse ritmo de utilização não está sendo acompanhado em discussões relacionadas às abordagens teóricas e práticas inerentes a esses recursos. Além das discussões emergentes nesse sentido, pesquisas relacionadas aos arranjos didático-pedagógicos, de recursos em formato digital estão longe de serem satisfatórias.

Diante do exposto, essa área carece de esclarecimentos no que diz respeito aos aspectos técnicos relacionados à interface de apresentação, em recursos digitais para o ensino da Química, visto que a utilização desses recursos pode favorecer a participação e o interesse dos estudantes nas atividades de ensino e aprendizagem (GIORDAN, 2013). É plausível considerar o apoio trazido pelos recursos de tecnologias 
digitais no contexto educacional, o qual vem se intensificando dia após dia, bem como a disponibilidade de recursos de simulação e laboratórios virtuais para representações de fenômenos químicos.

No entanto, os recursos de tecnologias digitais no espaço educacional são dignos de atenção, uma vez que a importância desses materiais, em formato virtual, pode favorecer a elaboração conceitual e a ampliação da capacidade de representação dos estudantes (SILVA; BRASILEIRO, 2015). Dessa forma, as representações oferecidas por meio de laboratórios virtuais, assim como os elementos visuais para representações com softwares, precisam ser permanentemente discutidas. Segundo Farias (2007, p.57), esta conjectura "implica dar a visualização um significado no processo de transformação, compreensão e interpretação dos conceitos" no ensino das ciências.

De acordo com Benite et al. (2010), o computador reúne atributos por meio de formas para representação da natureza Química, uma vez que possibilita a simulação das representações da realidade como ato comunicativo. Dessa forma, Farias (2007) sugere aos professores estarem atentos para a interpretação de figuras, de gráficos, de ícones e de símbolos pertencentes ao material quantitativo projetados na tela do computador de maneira correta.

Assim, o presente trabalho busca analisar representações quantitativas presentes nas interfaces de três laboratórios virtuais para o ensino de Química à luz da semiótica Peirceana. Trata-se de uma pesquisa de natureza qualitativa com nuances procedimentais exploratórios, realizada no repositório de aplicativos disponíveis no portal $\mathrm{PhET}$ - Interative Simulation.

\section{Material e Métodos}

Para a presente pesquisa se adotou a abordagem qualitativa, de caráter exploratório, que buscou analisar as representações quantitativas na perspectiva da semiótica inerentes aos laboratórios virtuais desenvolvidos para o ensino de química e disponíveis no repositório de aplicativos do portal PhET interactive simulation (2019).

Os repositórios digitais são considerados espaços virtuais nos quais ficam armazenados os objetos de aprendizagem. No aspecto da disponibilidade, os repositórios podem ser entendidos como banco de dados por meio dos quais é possível localizar e obter recursos educacionais para diferentes níveis de ensino e disciplinas. Alguns repositórios digitais podem solicitar alguns dados para realizar uma busca, como: nível de ensino, componente curricular, área ou disciplina como no caso específico o portal PhET interative Simulation, um site na web que disponibiliza recursos didáticos digitais úteis para os processos de ensino e aprendizagem. Entretanto, existem aqueles que servem para armazenar, preservar, organizar e difundir os resultados da produção intelectual de comunidades científicas, tendo como características o acesso público transparente, conteúdo heterogêneo e multidisciplinar
(LEITE, 2015).

$\mathrm{Na}$ presente pesquisa, foram objetos de análise os laboratórios virtuais disponíveis para o ensino de química no repositório de aplicativos do portal PhET interative Simulation. No entanto, inicialmente se buscaram os aplicativos desenvolvidos para área de química, resultando um total de 51 aplicativos.

Considerando os critérios elencados anteriormente, que distinguem recursos de animações, de simuladores e de laboratório virtual, foram classificados entre aqueles presentes no repositório PhET, por meio dessas observações seis aplicativos que se enquadram como laboratório virtual, porém somente os três primeiros foram analisados no campo da semiótica por abordarem os elementos quantitativos suficientes mostrados no Quadro 1 e ao escopo da pesquisa, os quais seguem listados por seus respectivos nomes no portal.

Quadro 1 - Relação de Laboratórios Virtuais disponíveis para química no repositório do portal PhET

\begin{tabular}{|l|l|}
\hline \multicolumn{2}{|c|}{ Laboratório Virtual } \\
\hline 1 & Concentração \\
\hline 2 & Densidade \\
\hline 3 & Sais e Solubilidade \\
\hline 4 & Forma de energia e transformações \\
\hline 5 & Ph básico da escala \\
\hline 6 & Soluções de açúcar e sal \\
\hline
\end{tabular}

Assim, após listada no Quadro 1, a relação de laboratórios virtuais, se passa a analisar em cada um as representações quantitativas presentes nas interfaces de alguns laboratórios virtuais para o ensino de Química no campo da semiótica Peirciana.

\section{Resultados e Discussão}

\subsection{Laboratórios Virtuais para o Ensino de Química}

Os laboratórios virtuais despontam como potenciais recursos alternativos a serem inseridos no planejamento de aulas de diversas disciplinas, em sua maioria, esses são gratuitos e podem ser utilizados de forma irrestrita. De acordo com Schmitt e Tarouco (2008, p.4):

o laboratório, nos cursos de tecnologia, não tem apenas a função de promover a constatação prática daquilo que é aprendido na teoria, de ilustrar e validar matéria estudada, ou de antecipar a prática profissional.

Nessa concepção, convém compreender que quando o laboratório virtual é desenvolvido para o ensino de Química, este pode se revestir de contribuições relevantes. Alguns simulam situações experimentais, que em muitos casos seriam inacessíveis de forma real (âmbito físico) por demandarem, em alguns casos, alto custo financeiro e apresentar risco ou efeitos temporais inviáveis quando aos níveis fenomenológicos (SCHMITT; TAROUCO, 2008). Por outro lado, alguns pontos são merecedores de atenção, pois vale lembrar que se trata de 
modelos que representam situação reais, e usar a simulação não garante, por si só, a compreensão conceitual na sua totalidade.

Segundo Brasileiro e Silva(2015,p.41): "como as simulações são baseadas em modelos de situações reais, é importante que esses modelos e os limites de sua validade estejam bem claros para o professor e para os estudantes". Nesta mesma linha de pensamento, o laboratório virtual se baseia em simulações e podem serem considerados objetos de aprendizagem (MACIEL; BACKES, 2013). Trata-se de um ambiente de ensino e de aprendizagem, que pode ser uma alternativa ao laboratório tradicional, aos instrumentos e materiais reais, porém de maneira virtual, oferece representações computacionais da realidade. Além disso, se configuram espaços de aprendizagem que permitem alcançar elaborações científicas e situações experimentais incompatíveis aos objetivos pretendidos para laboratórios presenciais instrucionais (SCHMITT; TAROUCO, 2008).

Nessa conjuntura, de acordo com Amaral et al. (2011), não há limitação em termos de números, instrumentos disponíveis nesta modalidade, além de não haver essencialmente uma autenticação por parte dos alunos, nem tampouco momento específico para se utilizar laboratórios virtuais e sem maiores restrições. Os laboratórios virtuais de aprendizagem estão dispostos em plataformas digitais e no quesito mobilidade dão suporte à realização de experiências dispensando a necessidade da presença do aluno em um local específico, assim como ocorre nos laboratórios reais.

As potencialidades do uso das tecnologias digitais, no âmbito mobilidade, interatividade e representação para a educação, podem ser vistas a partir da variedade de possíveis usos, apresentando-se como recursos de animação, de simulação e de laboratórios virtuais. Muito embora pontuando os laboratórios virtuais de aprendizagem como ambiente alternativo ao laboratório tradicional, importa também questionar quais seriam os elementos bases para classificar um laboratório virtual para ensino de química? Ainda, neste pensamento, questiona-se quais são os critérios de classificação que justificam distinguir os aplicativos em recursos de simulação, de animação e de laboratórios virtuais para o ensino de química? Nesta perspectiva, são consideradas as concepções teóricas de Melo e Melo (2005); Paula (2015); Giordan (2013) e Brasileiro e Silva (2015), que discorrem sobre as características que diferenciam os recursos de animação, de simulação e de laboratórios virtuais. Baseados nos princípios e critérios de distinção se reuniu ao conjunto de investigação buscando atender o objetivo proposto da pesquisa.

Entre as principais características para classificação dos recursos de animações, de simulações e de laboratórios virtuais estão o grau de interatividade entre o estudante e o software. Segundo Paula (2015), quando tais recursos atuam como mediadores nos processos de ensino e aprendizagem, tende haver interação entre o sujeito aprendiz com o objeto de aprendizagem ${ }^{1}$, entretanto no caso das animações o grau de interatividade é quase nulo. Já no caso das simulações, a interatividade existente entre o estudante e o objeto de aprendizagem pode oscilar entre baixo e médio.

Nas simulações "existem variáveis que podem ser alteradas pelo estudante permitindo a observação de diferenças nos comportamentos dos objetos ou materiais e nos tipos de eventos que são representados na tela do aplicativo" (PAULA, 2015, p.186). Ainda se referindo às simulações, Melo e Melo (2005, p.5) salientam que em uma simulação se deva representar um sistema real, seguindo as "teorias ou modelos que o descrevem, ou seja, são representações de um sistema que a teoria supõe ser real, que possibilitam interações sem as limitações ou perigos que o sistema real possa ter".

Todavia, tanto os recursos de simulação, quando os de animação podem trazer benefícios para o estudo da química, no sentido de que os professores consigam proporcionar condições aos alunos de compreender os fenômenos estudados.

Ainda assim, por meio dos laboratórios virtuais, os estudantes podem observar fenômenos modelados a nível macroscópico, coletar dados, isolar variáveis e estudar o comportamento de sistemas (BRASILEIRO; SILVA, 2015). Nessa mesma perspectiva, o grau de interatividade é maior em relação aos anteriores, permitindo que o aluno realize experimentos similares àqueles realizados em um laboratório real (PAULA, 2015). Nas concepções de Giordan (2013), os laboratórios virtuais representam uma combinação de característica iconográfica, que contextualizam experimentos e situações fenomenológicas, transpondo do fenômeno do meio natural para o computador.

Existem outros dois critérios de distinção desses recursos de tecnologias digitais, sendo que um desses está relacionado com as informações produzidas. No caso dos recursos de simulação, esses podem apresentar informações quantitativas, porém essa não é uma atribuição específica e obrigatória desse recurso. Já os laboratórios virtuais trazem realização de medidas, reproduzem resultados provenientes da interação do estudante com recursos e comandos na interface do recurso. Segundo Paula (2015), os tipos de representações também são critérios que os diferenciam, mais especificamente no tipo de objeto que essas representações substituem. Para os laboratórios virtuais, são mais comuns representações de objetos e de eventos que pertençam aos fenômenos reais, "ao mundo do laboratório", enquanto nas simulações predomina a representação de entidades e processos que constituem os modelos científicos, ou seja, que pertença ao mundo concebido pelas ciências. O Quadro 2 apresenta sucintamente, atributos de cada objeto de aprendizagem, baseado nas concepções teóricas de (PAULA, 2015).

1 Objetos de Aprendizagem como sendo aqueles "disponíveis na web, que utilizam a tecnologia como forma de construção e implementação, tais como os vídeos, os filmes, as animações, slides, enfim os materiais didático-tecnológicos elaborados e/ou disponíveis aos docentes”. (MACIEL; BECKES, 2013, p.178). 
Quadro 2 - Critérios que distinguem recursos de animação, simuladores e laboratórios virtuais para o ensino de química.

\begin{tabular}{|c|c|c|c|}
\hline $\begin{array}{c}\text { Objeto de } \\
\text { Aprendizagem }\end{array}$ & $\begin{array}{c}\text { Grau de } \\
\text { Interatividade }\end{array}$ & Informações Produzidas & Tipos de Representações \\
\hline $\begin{array}{l}\text { Recursos de } \\
\text { animação }\end{array}$ & Baixo & $\begin{array}{l}\text { Informações equivalentes às descrições ou } \\
\text { narrativas }\end{array}$ & Não incide \\
\hline Simuladores & Médio ou alto & $\begin{array}{l}\text { Combinação de um conjunto de varáveis; } \\
\text { Reprodução de leis que interpretam um } \\
\text { fenômeno. }\end{array}$ & $\begin{array}{l}\text { Mundo concedido pelas ciências } \\
\text { Modelos científicos; Baseado em uma } \\
\text { teoria }\end{array}$ \\
\hline Laboratório virtual & Alto & $\begin{array}{|ll|}\text { Informações } & \text { quantitativasAltera } \\
\text { variáveisRealização de medidas }\end{array}$ & $\begin{array}{l}\text { Representação formal dos laboratórios } \\
\text { reais, pertence ao mundo vivido }\end{array}$ \\
\hline
\end{tabular}

Fonte: adaptado de Paula (2015).

Os laboratórios virtuais representam uma combinação de característica iconográfica, além do alto grau de interatividade que proporcionam ao contextualizar conceitos disciplinares. Isso o faz ser largamente utilizado para estudos científicos, sobretudo quando se considera a transposição do fenômeno do meio natural para o computador (GIORDAN, 2013). Ainda assim, o autor supracitado sustenta que são três aspectos de transposição desses fenômenos: "a reprodução em tela do fenômeno filmado, a animação obtida pela sequência de ilustrações e a simulação por meio de combinação de um conjunto de variáveis de modo a reproduzir leis que interpretam o fenômeno" (GIORDAN, 2013, p.125). Para tanto, tais atributos reúnem os elementos que integram a transposição, e requer observação permanente para que possa servir de referência e contribuir como recurso didático.

\subsection{Representações no campo da Semiótica}

As representações permitem que objetos e eventos ausentes em um dado contexto sejam concebidos e também visualizados, por meio das tecnologias digitais, como pontes entre a realidade vivenciada pelos estudantes e os mundos concebidos pelas ciências. Nessa direção, as representações têm um importante papel para visualização de conceitos químicos, tanto por imagens produzidas na tela do computador, quanto às reproduzidas no papel (FARIA, 2007).

No que se refere à visualização, Wartha e Rezende (2011, p.6) a denominam "sinais visuais estáticos e dinâmicos (de símbolos para ícones) desenvolvidos para facilitar o pensamento qualitativo e quantitativo e a comunicação sobre experiências e modelos em química". Todavia, para o ensino de conceitos químicos se considera a visualização importante e necessária para o tratamento de símbolos químicos, fórmulas, equações matemáticas, gráficos animações, simulações e modelos físicos. Tais aspectos integram a visualização de representações do modelo teórico.

Assim, a semiótica se dispõe a analisar essas representações, bem como as inter-relações existentes entre signo, objetos e representações na perspectiva de Charles Sanders Peirce ${ }^{2}$. Dessa forma, para Santaella (2002, p.9), a semiótica "é a ciência que tem por objeto de investigação todas as linguagens possíveis, ou seja, que tem por objetivo o exame dos modos de constituição de todo e qualquer fenômeno de produção de significação e de sentido".

Ainda, nesta linha de pensamento, segundo Santaella (2002, p. 35), a semiótica surge como uma área de estudo que tem por objeto de investigação os signos. Para esta autora, "o signo é uma coisa que representa uma outra coisa: seu objeto. Esse só pode funcionar como signo se carregar esse poder de representar, de substituir uma outra coisa diferente desse. Esse apenas está no lugar do objeto". O que caracteriza um signo, segundo Paula (2015), é o resultado da interação entre uma representação, um objeto representado (palavra, imagem, vídeos, simulação virtual), também chamado de referente do signo e algo (um software) ou alguém (estudante, professor) que irá associar a representação ao objeto ou ao evento representado, também chamado de interpretante.

Segundo Wartha e Rezende (2011, p.6), "na Semiótica Peirciana, é o signo que desencadeia a representação, uma vez que esse é percebido como sendo, algo que, sob certo aspecto ou de algum modo, representa alguma coisa para alguém".

As inter-relações existentes entre signo, objetos, representações e suas implicações para os processos de ensinar dão para a semiótica um papel importante e a intitula como área do conhecimento que se encarrega de estudar os processos de produção, de circulação, e de interpretação de signos.

Nas concepções de Miskulin (2007, p. 4), no campo da semiótica há uma relação triádica:

A Semiótica, portanto, procura estabelecer os modos de compreender os signos e, para que uma definição seja bem interpretada, convém esclarecer que um signo, na concepção de Peirce, mantém uma relação triádica, uma vez que um primeiro, seu representante, estabelece uma relação com um segundo, seu objeto, o qual estabelece uma relação com um terceiro, seu interpretante.

Para Miskulin (2007), a relação triádica peirceana ou triadicidade, encontrada na base dessa teoria, parte da concepção de que a experiência do fenômeno pode ser sempre reduzida de forma a apresentar três tipos de propriedades,

2 C. S. Peirce (1839-1914) era, antes de tudo, um cientista. Aos 11 anos escreveu uma História da Química; e em Química se bacharelou na Universidade de Harvard. Mas Peirce era também matemático, físico, astrônomo, além de ter realizado contribuições importantes no campo da Geodésia, Metrologia e Espectroscopia. Era ainda um estudioso dos mais sérios tanto da Biologia quanto da Geologia, assim como fez, quando jovem, estudos intensivos de classificação zoológica sob a direção de Agassiz (SANTAELLA, 2002, p.11). 
Qualidade (Primeiridade), Relação (Secundidade) e Representação (terceiridade). Desse modo, em relação a um signo utilizado como objeto no ensino da Química por aspectos quantitativos, a primeiridade pode ser exemplificada quando um aluno visualiza na interface de um laboratório virtual, um marcador numérico presente em um display, ou a graduação no recipiente simulado, sem fazer referência a nada, somente aos registros apresentados e, nesse caso, há somente uma primeira impressão. A secundidade estar relacionada ao signo, ou seja, associação de ideias, determinação e a ação e reação. De modo que quando o aluno observa um gráfico ou valores numéricos em conjunto aos componentes do laboratório virtual, em seguida, relaciona as variações de concentração, aumento de temperatura, massa, volume ao propósito do laboratório em questão. Nesse momento, o aluno se depara com o problema e a existência de algo a e ser investigado. No caso da terceiridade, essa construção implicam nas interpretações, o efeito gerado pelo aluno, bem como explicações das informações (WARTHA; REZENDE, 2011).

De modo específico, as potencialidades semióticas quantitativas em laboratórios virtuais, no contexto educacional, se despontam promissoras. Contudo, a forma de representar conceitos e objetos quantitativos, em ambiente virtual, na perspectiva da semiótica, leva a pensar em abordagens que envolvam uma variedade de linguagens que, por sua vez, se fundamenta em signos, sendo esses códigos, imagens, símbolos, sons e movimentos, próprios para representar essas entidades (FARIAS, 2007).

A esse respeito, Giordan (2013, p. 95) exemplifica que a "equação química, devido ao seu poder de síntese e de combinação de elementos semióticos originais, merece um estudo à parte à luz da perspectiva sociocultural”, pois a possibilidade de ser utilizada para abordar o mundo macroscópico e microscópico faz emergir uma série de questões do ponto de vista dos signos a serem representados em sala de aula. Ainda, segundo Giordan (2013), em função das propriedades sensoriais, os fenômenos macroscópicos são mais facilmente descritos e quantificados por recursos ou experimentos construídos em espaços de aprendizagem e/ou atividades que lhe são familiares.

No contexto educacional, identifica-se uma mobilidade crescente de representações. Tal condição, de acordo com Miskulin et al. (2017), parece estar assegurada pela atual disponibilidade de recursos oriundos das tecnologias digitais de informação e de comunicação, ou seja, há possibilidade de tradução das representações de uma modalidade para outra. A concepção de um determinado ambiente virtual, sob a grandeza da Semiótica, "significa conceber o pensamento na direção do entendimento das possibilidades pedagógicas desse ambiente no processo de representação de um conceito ou de um pensamento" (MISKULIN et al., 2007, p.11).

De todo modo, segundo Farias (2007), para as interpretações numéricas, a visualização se constitui uma alternativa de acesso ao seu conhecimento. Nesse contexto, para que haja apropriação de conceitos quantitativos, múltiplas representações são convenientes para aprendizagem. Cabe lembrar que a representação visual se torna parte desse processo, transformando o entendimento em si. Os ambientes virtuais de ensino e aprendizagem dispõem de interfaces que podem colaborar nesse processo, no entanto, seu uso em conceitos químicos requer auxílio para compreensão dos eventos visuais representados.

\subsection{Descrição e Análise dos Dados}

O estudo expositivo de cálculos, de equações, de repetição de fórmulas e mecanismos de reações não deveriam ser o objetivo principal no ensino e aprendizagem de Química, mas sim, elementos complementares, pois corroborando com Wartha e Rezende (2011), o mais importante seria o desenvolvimento da imaginação, ou seja, criar modelos explicativos por meio da capacidade de representar átomos, moléculas, transformações químicas, e assim, usá-los na construção do conhecimento químico, considerando os aspectos quantitativos inerentes a cada caso em específico.

\subsection{Laboratório Virtual: Concentração}

Alguns laboratórios virtuais utilizados em sala de aula reúnem esses atributos e podem se tornar recursos pedagógicos aliados de professores, seja para discussões conceituais de fenômenos, seja para complemento relacionados aos conteúdos estudados em sala de aula (SCHMITT; TAROUCO, 2008). As interfaces de alguns laboratórios virtuais desenvolvidos para o ensino de química trazem representações quantitativas, que podem auxiliar na interpretação do objeto representado no âmbito virtual. Estes são acessórios adicionais que enriquecem as representações como apresentado na Figura 1.

Figura 1 - Interface do laboratório virtual "Concentração"

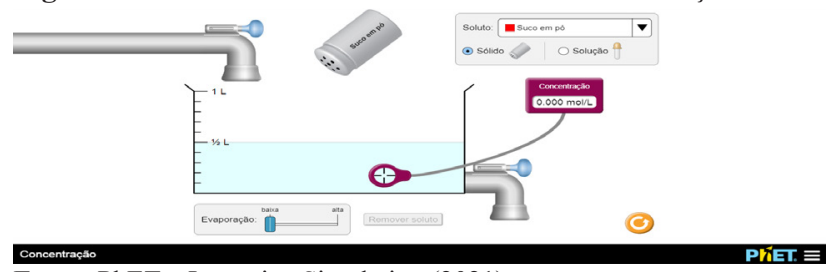

Fonte: PhET - Interative Simulation (2021).

Entre os objetivos que compreendem o laboratório virtual supracitado estão: descrever as relações entre volume e quantidade de soluto no meio, que corresponde a concentração da solução, criar um procedimento para a criação de uma solução de uma dada concentração, identificar quando uma solução está saturada, bem como prever a mudança da concentração mediante qualquer ação ou conjunto de ações que alterem o soluto ou o solvente (Figura 1).

O referido laboratório virtual aborda o estudo das soluções, das concentração, da saturação, da molaridade, do volume e solubilidade, porém apresenta apenas, numericamente, 
instrumentos que reúnem volume e quantidade de soluto na concentração da solução (Figura 1). Não há qualquer objeto representado e instrumentos de massa do soluto. Nesse sentido, Miskulin et al. (2007, p.8) afirmam que "a instrumentalidade de representação garante ao sujeito a possibilidade de refletir sobre os objetivos e meios com os quais atua".

Quanto ao laboratório supracitado, no âmbito da semiótica, se observa ausência de signos (dispositivos) para compreensão de entes químicos que poderiam se interrelacionar nos espaços quantitativos proporcionando reflexões. Nas representações numéricas, que correspondem ao volume, essas têm mínima precisão, demostrando volumes apenas na faixa de 0,5 litro e 1 litro impossibilitando alcançar exatidão quantitativa de volume. Tais constatações podem elevar as dificuldades quando se buscam avanços de Primeiridade, Secundidade e Terceiridade, para identificação da objetivação. Além disso, denota-se maior ênfase para a forma qualitativa como a concentração da solução que muda para qualquer ação quando se adiciona ou remove solvente (água), soluto ou solução. Assim, para o laboratório virtual em questão se sugere a representação de um signo iconográfico quantitativo inerente à massa do soluto para que possa haver maior relação do signo com o interpretante.

Segundo Wartha e Rezende (2011), deve-se estabelecer a relação de significação, de objetivação e de interpretação quando se busca a compreensão por parte dos estudantes com relação ao estudo das concentrações, ou seja, ao observarem signos iconográficos de natureza quantitativa, que representam algo em lugar de outra coisa, as possibilidades dos estudantes são ampliadas ao estudarem o problema. Sob o ponto de vista da visualização, Farias (2007) argumenta que contribui para interpretações quantitativas e acesso ao conhecimento, mas por outro lado, convém ressaltar que o laboratório virtual "Concentração" carece de signos representativos no espectro visual quantitativo, assim como diagramas, equações ou gráficos para enriquecimento de grandezas no campo da química.

Entretanto, esse laboratório virtual possui limitações aparentes e pode ser um recurso didático importante, no qual o professor pode se apoiar como complemento em suas práticas pedagógicas, ao passo que pode ser usado como uma ponte entre a realidade que vivenciam os estudantes e o mundo concebido pelas ciências.

\subsection{Laboratório Virtual: Densidade}

Os laboratórios virtuais têm por finalidade representar situações reais por meio de simulação, no entanto Brasileiro e Silva (2015) alertam para a importância de considerar nos modelos (ícones), os limites de sua validade para que estejam claros para o professor e estudantes. Convém esclarecer que se trata de um tipo de representação, assim se tem o papel de promover significação por semelhança de propriedades entre os ícones objetos moleculares, fenômenos, transformações e seu objeto concreto (ente molecular, substâncias e fenômenos).
Nesse caso, o laboratório virtual "Densidade" (Figura 2) toma como signos os elementos que compreendem a densidade, aludindo o fato das representações se constituírem, prioritariamente, em figuras, construídas por atributos interativos.

Figura 2 - Interface do laboratório virtual "Densidade"

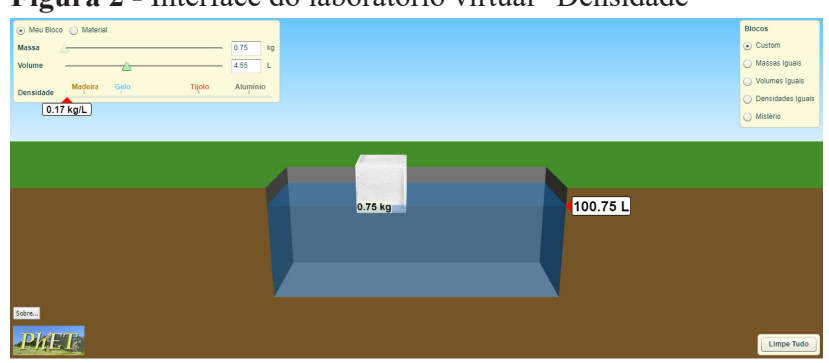

Fonte: PhET - Interative Simulation (2021).

Outra característica conferida a esse laboratório virtual se relaciona ao fato de que os dispositivos quantitativos, além de estarem ilustrados em um display, no canto superior esquerdo, também aparecem agrupados aos objetos que compõem o sistema, dispostos em uma ordem satisfatória (Figura 2). Nesse sentido, Miskulin et al. (2007) assinalam para uma relação indissociável entre a representação e seu caráter semiótico, além de uma mobilidade crescente de representações, fator que amplia as possibilidades dos processos quantitativos e reflete em possíveis relações entre a imagem conceitual e a imagem de uma determinada figura com ilustrações quantitativas.

É importante ressaltar os aspectos interativos presentes neste laboratório virtual, além de representar ícones das leis da física, que regem a grandeza "densidade" apresenta suas variáveis, representando visualmente o fenômeno e seus signos na tela inicial. No entanto, vale lembrar que do ponto de vista da semiótica, "um signo não é um objeto, ele apenas está no lugar do objeto, fazendo referência ao objeto, de maneira que ele só pode representar esse objeto de um certo modo e em uma certa capacidade" (FARIAS, 2007, p.37).

Assim, para o ensino de química, a visualização se configura decisiva para a compreensão de símbolos químicos, fórmulas, equações matemáticas, gráficos, animações, simulações e modelos físicos. De acordo com Wartha e Rezende (2011), as categorias (primeiridade, secundidade e terceiridade) não são fixas e se pode encontrar estudantes que, inicialmente, não consigam fazer relações entre as categorias, nesse caso, a representação mental do estudante será gradual, a começar pelo ícone, evoluindo para índice e, consequentemente, alcançará o símbolo. Entretanto, tais avanços não se configuram uma regra, a evolução de uma categoria para outra constitui em sistemas formais complexos interpretados.

Entende-se que classificar os signos de aspectos quantitativos do laboratório virtual como inadequados, ausentes de representações seria uma afirmação incompleta, que ignora a ampla variedade de usuários, formas de representação que permeiam sua criação. No caso do 
laboratório virtual dotado de elementos representacionais, que contribuem para os processos de ensino e aprendizagem e se trata de um construto teórico resultado da moderna aliança do conhecimento químico teórico e experimental.

Ademais, um ambiente virtual dessa natureza que contém representações quantitativas resultantes de experimentos químico ou físico, precisam estabelecer harmonia para a combinação de formas referentes ao objeto de estudo, criando assim, um ambiente de simulação, no qual se tenham signos que representem objetos suficientes para o interpretante.

Por fim, o laboratório virtual "densidade" apresenta sinais visuais dinâmicos que convergem com as concepções de Wartha e Rezende (2011), pois além de estimular o pensamento quantitativo também corrobora com a comunicação sobre experiências e modelos da química.

\subsection{Laboratório Virtual: Sais e solubilidade}

O laboratório virtual "Sais e Solubilidade" (Figura 3) permite ao estudante desenvolver práticas, por meio de sua interação, verificando a ocorrência de um determinado fenômeno de maneira simplificada da realidade. Para o ensino de química, os laboratórios virtuais surgem como recursos de extrema importância, pois permitem ao aluno conhecer fenômenos naturais, compreender causas e efeitos, que em muitos casos seriam inalcançáveis em laboratórios reais (PAULA, 2015).

O objetivo do Laboratório virtual "Sais e Solubilidade", de maneira específica, é proporcionar aos alunos a possibilidade de colocar a solubilidade de diferentes sais em ordem, determinar a razão de ânions e cátions, que criam um composto neutro e calculam a molaridade de soluções saturadas e valores de Kps (coeficiente do produto de solubilidade). Com isso, espera-se que o estudante possa estabelecer relações quantitativas entre soluto e solvente.

Figura 3 - Interface do laboratório virtual "Sais e solubilidade".

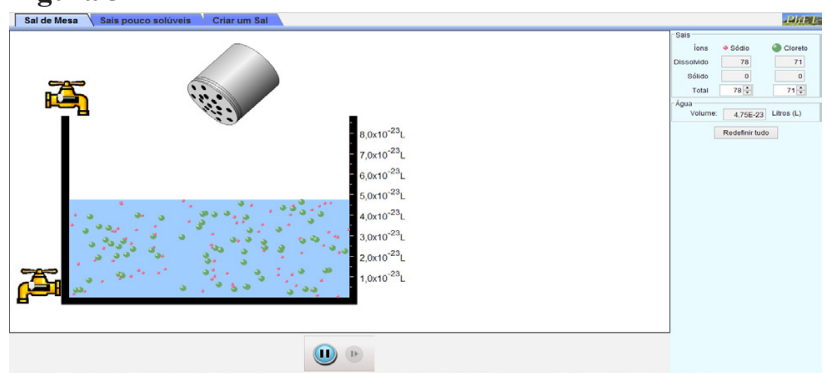

Fonte: PhET - Interative Simulation (2019).

Um fato interessante desse laboratório virtual é que o mesmo apresenta as partículas de sais de forma escrita (nomenclatura) e por um modelo de aglomerado iônico microscópico, representado por esferas de cores diferentes ilustrativas referentes aos átomos que formam os cátions e os ânions, como mostrado na Figura 3.

Enquanto se agita o recipiente contendo o sal se observa entre os fenômenos os aglomerados do respectivo sal emergindo na solução, a dissolução das partículas e a dissociação dos sais ocorrendo em nível atômico-molecular. Além disso, no aspecto quantitativo, o sujeito acompanha o efeito causado pelo fenômeno da dissolução em um recipiente graduado em volumes equivalentes ao mínimo dos compostos de aglomerados iônicos, assegurando confiabilidade conceitual e possibilitando o cálculo da constante Kps.

Diante do exposto, pode-se afirmar que a aplicabilidade química desse laboratório virtual se encontra em harmonia com princípios básicos quantitativos no campo da representação desse ambiente computacional. Sob a dimensão da semiótica, o laboratório favorece a percepção do interpretante e segue na direção do entendimento das possibilidades pedagógicas desse ambiente no processo de representação de conceitos (MISKULIN et al., 2007).

A evidência da centralidade dos sistemas semióticos para o desenvolvimento conceitual dos estudantes é ressaltada por Giordan (2013), em que o estudo da estrutura e composição da matéria e da teoria molecular carece de variadas formas de representação, sem as quais a elaboração de conceitos pelos estudantes estaria comprometida.

No ponto de vista da semiótica, tanto os valores numéricos mostrados em notações científicas no recipiente, quanto aos dados quantitativos dos íons apresentados no display, à direita na tela do computador (Figura 3), atuam como signos, ou seja, aquilo que representa algo em lugar de outra coisa. Cabe enfatizar que o signo compreende uma relação, entre signo, objeto e interpretante. $\mathrm{O}$ objeto é aquilo que o signo determina e representa. Nesse caso, o interpretante é o efeito interpretativo que o signo produz em uma mente real ou simplesmente potencial (FARIAS, 2007; SANTAELLA, 2002).

No contexto quantitativo, demonstrado no respectivo laboratório virtual, inerentes ao solvente e ao soluto se configuram objeto dinâmico desse signo, pois estes dados numéricos dão condições e se elevam para que o interpretante estabeleça relações quantitativas para compreender sua essência (FARIAS, 2007).

No caso de cálculos químicos oferecidos pelo laboratório virtual, depois de apresentar signos iconográficos de variáveis da equação química na aplicação da lei de conservação da matéria, convém atentar-se ao uso da equação química para reconhecer a relação de proporcionalidade entre reagentes e produto, o que normalmente é tratado como lei específica ou lei das proporções definidas. Nesse caso, o soluto e o solvente que são representados no laboratório virtual por ícones, assim como as substâncias devem aconselhavelmente ser convertidos em quantidade de matéria simbolicamente, aplicando-se uma outra lei, ou também chamada de hipótese de Avogadro.

\section{Conclusão}

As representações quantitativas analisadas nos três laboratórios virtuais sugerem aos usuários que controlem variáveis numéricas, e que percebam as vantagens em 
se utilizar esse recurso, além da facilidade no acesso de resultados de um experimento sem que, para isso, o tenha que realizar fisicamente.

Contudo, os laboratórios virtuais analisados à luz da semiótica demonstram confiabilidade nos elementos que constituem os signos e disposição satisfatória das representações quantitativas. Ademais, nota-se a incompletude de signos na interface dos laboratórios virtuais no âmbito quantitativo, que pode vir a comprometer a compreensão dos processos envolvidos na interpretação dos signos não verbais.

Pode-se inferir que a aplicabilidade em processos de ensino e aprendizagem de química dos referidos laboratórios virtuais se mantiveram em harmonia com princípios quantitativos nesse ambiente virtual. Por outro lado, ausência de signos (dispositivos) que poderiam auxiliar nos espaços quantitativos estão entre as limitações identificadas para que seja estabelecida a relação triádica por parte do estudante usuário do laboratório virtual.

No entanto, para o ensino de Química se pode ressaltar que o uso desses recursos de tecnologias digitais pode ser largamente utilizado, de modo que enriqueça as discussões teóricas e se configure suporte para as práticas pedagógicas, admitindo que as experiências cotidianas dos alunos ganhem sentido, facilitando os estudos sobre os conteúdos pertinentes à ciência Química.

\section{Agradecimentos}

Ao CTMAT da UNEMAT Barra do Bugres, CAPES e a SEDUC-MT pelo apoio no desenvolvimento do presente estudo.

\section{Referências}

AMARAL, É. et al. Laboratório virtual de aprendizagem: uma proposta taxonômica. RENOTE, v.9, n.2, 2011. doi: https://doi. org/10.22456/1679-1916.24821

BENITE, A.C.M.; BENITE, C.M.R.; SILVA FILHO, S.M. Cibercultura em Ensino de Química: Elaboração de um objeto virtual de aprendizagem para o ensino de modelos atômicos. 2011. Disponível em: < https://repositorio.bc.ufg.br/xmlui/ handle/ri/14875> Acesso em 30 set. 2020.
BRASILEIRO, L.B.; SILVA, G.R. Interatividade na ponta do mouse: simulações e Laboratórios virtuais. In: MATEUS A.L. (Org.). Ensino de Química mediado pelas TICs. Belo Horizonte: UFMG, 2015.

FARIAS, M.M.R. As representações matemáticas mediadas por softwares educativos em uma perspectiva semiótica: uma contribuição para o conhecimento do futuro professor de matemática. Rio Claro: Universidade Estadual Paulista, 2007.

GIORDAN, M. Computadores e linguagens nas aulas de ciências: uma perspectiva sociocultural para compreender a construção de significados. Ijuí: Unijuí, 2013.

KENSKI, V.M. Tecnologias e ensino presencial e a distância. Campinas: Papirus, 2012.

LEITE, B.S. Tecnologias no ensino de química: teoria e prática na formação docente. Curitiba: Appris, 2015.

MACIEL, C.; BACKES, E.M. Objetos de aprendizagem, objetos educacionais, repositórios e critérios para a sua avaliação. In: MACIEL, C. (Org.). Educação à distância: ambientes virtuais de aprendizagem. Cuiabá-MT: EdUFMT, 2013. p.159-196

MELO, E.N.S.; MELO, J.F.R. Softwares de simulação no ensino de química: uma representação social na prática docente. ETD-Educação Temática Digital, v.7, n. 1, p. 51-63, 2005. doi:10.20396/etd.v6i2.773

MISKULIN, R.G.S. et al. A semiótica como campo de análise para as representações de conceitos matemáticos. Casa, v.5, n.2, 2007. doi: https://doi.org/10.21709/casa.v5i2.548

PAULA H.F. As tecnologias de informação e comunicação, o ensino e a aprendizagem de ciências naturais. In: MATEUS Alfredo Luís (Org.). Ensino de Química mediado pelas TICs. Belo Horizonte: UFMG, 2015.

PHET Interative Simulation. Disponível em: < https://phet. colorado.edu/pt_BR/>. Acesso em: 27 mar. 2020.

RIBEIRO, M.E.M. et al. Natureza epistemológica dos objetos de aprendizagem para ensino de química no ensino médio. Rev. Ensin. Educ. Ciênc. Hum., v.17, n.3, p.245-250, 2016. doi: https:// doi.org/10.17921/2447-8733.2016v17n3p245-250

SANTAELlA, L. O que é semiótica. São Paulo: Brasiliense, 2002.

SCHMITT, M.A.R.; TAROUCO, L.M.R. Metaversos e Laboratórios Virtuais: possibilidades e dificuldades. RENOTE, 2008. doi: https://doi.org/10.22456/1679-1916.14577

WARTHA, E.J.; REZENDE, D.B. Os níveis de representação no ensino de química e as categorias da semiótica de Peirce. Investig. Ações Ensino Ciênc. v.16, n.2, p.275-290, 2016. 